\title{
AN EXPLORATIVE REVIEW OF E-LEADERSHIP STUDIES
}

\author{
Oh Siew Pei ${ }^{\mathrm{a}^{*}}$, Chua Yan Piaw ${ }^{\mathrm{a}}$ \\ aInstitute of Educational Leadership, Faculty of Education, University of Malaya \\ "Corresponding Author Email: sp_oh90@hotmail.com
}

\begin{abstract}
This study aimed to explore the field of educational leadership and educational technology innovations. In order to understand the extent to which e-leadership was discussed, content analyses on selected conference papers, book chapters, thesis and professional journals spanning across 2000 to 2016 was conducted. An extensive review of the literature found a total of 45 articles mainly on e-leadership, virtual leadership, leading virtual teams, school ICT leadership and e-leaders in both education and non-educational setting. These articles focus on six main themes of $e$ leadership, which are challenges, leadership styles, trust building, training and development, culture, e-leader skills and guidelines. Findings indicate that empirical studies on e-leadership are scarce and more studies in this area need to be conducted in the digital era. In addition, a proposed model of e-leadership effectiveness and variables that are associated with e-leadership is included in this paper. Subsequently, the missing link for future studies is discussed.
\end{abstract}

Keywords: e-leadership, virtual leadership, school ICT leadership, e-leaders

\section{INTRODUCTION}

Since the mid-1990s, the idea that we live in a global knowledge economy has dominated policy talks at all scales including institutional, national, regional and global (Robertson, 2005). The language of globalization has quickly entered discourses about schooling and government talk about the necessity of schools meeting the needs of the global economy (Spring, 2008). As we know, education and the Internet are explicitly linked to innovation, global economic development and social development. Greater connectivity and technological advancement have enriched and expanded education for us.

The Internet era is a current force of change that is connecting education to the network and expanded education for us (Mohamad Mohsin, Hassan, \& Ariff, 2014). Adeyemi \& Olaleye (2010) noted that the prominent role of information and communication technology (ICT) could be seen in advancing knowledge and is a necessary skill for effective functioning in the modern world. ICT is becoming increasingly important in our daily lives and in our educational system. Therefore, there is a growing demand for educational institutions to use ICT to teach the skills and knowledge needed by 21st-century learners. Furthermore, Jameson (2014) stated that due to the accelerating growth in educational technology and social media usage, the environment experienced by pupils, staff, schools and parents is radically changing to the point that online 21st century technologies need to play a more significant role in education than ever before.

The arrival of digital technologies in schools has impacted the roles and responsibilities of principals in significant ways (Mohammed Sani, Ahmad Zabidi, \& 
Husaina Banu, 2013). Leithwood, Seashore, Anderson, \& Wahlstrom (2004) stated that principal's role has shifted from a narrow focus on management to a broader scope of leading student learning, reflecting the vision of building, facilitating and supporting practices of leadership to create change and continual educational improvement in school. Implementing ICT into schools is one of the responsibilities of school principals. Integrating ICT into education for the benefit of the whole community are the responsibilities of school principal too (Gronow, 2007).

Several studies (Avolio \& Kahai, 2003; Gurr, 2004; Pulley, Sessa, Fleenor, \& Pohlmann, 2001; Purvanova \& Bono, 2009; Savolainen, 2013) informed that ICTenabled economy is creating a new context for leadership. Avolio \& Kahai (2003) indicated that long established theories of leadership may not be sufficient for successful leadership practices in the ICT-mediated environment. Thus, the migration of leadership to e-leadership has been considered necessary in shielding any reform endeavours. Furthermore, research focused on e-leadership found that there is a gap between the practice and implementation of ICT and what we know about its effects of e-leadership and literature in e-leadership field is scarce (Avolio, Sosik, Kahai, \& Baker, 2014; DasGupta, 2011; Hambley, O'Neill, \& Kline, 2007; Hanna, 2007; Jameson, 2013; Lovelace, 2015).

In 2012, the Malaysian Education Blueprint was introduced to develop a new education vision and to generate a major transformation in Malaysia's education system (Ghani, 2013). The Blueprint also offers a vision of the education system and students that Malaysia both need and deserve. There are 11 operational shifts and strategies suggested in the blueprint that will help to achieve the vision of education plan. Shift number seven among the eleven shifts is related to the leverage of ICT to upgrade the quality of learning of Malaysia learners. Leong, Chua, Kannan, \& A. Maulod (2016) stated that school leaders play a significantly important role in making the vision for ICT implementation at all levels including school, district and national level. Thus, it is imperative to understand leadership in a virtual setting in order to achieve Malaysian government's vision to provide quality internet-enabled education for all. Further supported by Harris, Jones, \& Baba (2013) stated that there is a need to explore and understand leadership in a virtual setting as the establishment of a digital platform to support professional learning is now ubiquitous.

Through an extensive review of the e-leadership literature, Avolio, Kahai, \& Dodge (2000) indicated, "we chose the term e-leadership to incorporate the new emerging context for examining leadership" (p. 617). The authors defined e-leadership as a social influence process mediated by technology from a business and management perspective. They referred the ICT as Advanced Information Technology (AIT) and the definition is as below:

"E-leadership is defined as a social influence process mediated by AIT to produce a change in attitudes, feelings, thinking, behaviour, and/or performance with individuals, groups, and/or organisations. E-leadership can occur at any hierarchical level in an organisation and can involve one-to-one and one-to-many interactions within and across large units and organisations. It may be associated with one 
individual or shared by several individuals as its locus changes over time (Avolio et al., 2000, p.617)".

It is through literature review and understanding how a topic is being explored in a related field that allowed us to understand the importance placed on the specific topic (Mcleod \& Richardson, 2011). Through understanding how e-leadership is being explored in the field of educational leadership, it becomes clear the importance placed on this topic by researchers, policymakers and practitioners. By gaining an understanding of how e-leadership is being researched and discussed, it provides insight for researchers in this area for future research.

This study focuses on the topic of e-leadership from school leadership perspective. However, to understand the concept of e-leadership and the extent to which these topics are explored in leadership circles, this paper includes both educational and non-educational research on the e-leadership topic. Within this scope, the study is an analysis of a selection of educational leadership and non-educational journals, conferences paper, thesis and book chapter intended to determine the extent to which issues about e-leadership are being explored and discussed. The purpose of this review is to synthesize the scientific literature that has examined e-leadership in both educational and non-educational settings and to propose a model of eleadership practices and variables that are associated with e-leadership.

\section{METHODS}

This study reports on a review of prior research into e-leadership in both education and non-educational settings and a robust representation of the extent to which eleadership issues have been covered. Since the research on e-leadership domain is poorly understood and empirical studies on the topic are scare, exploratory review is one of the most suitable method (Hallinger, 2013). Thus, with the purpose to identify emerging themes and to propose a model of e-leadership practices as well as variables that are associated with e-leadership, this study referred to systematic review methodology proposed by Hallinger (2013). This method provide transparent with respect to research questions, the methods of identification of sources, data collection and data analysis (Walker \& Hallinger, 2015).

According to Hallinger (2013), conceptual framework helps reviewer to identify the type of data that will be collected and highlights potential interconnections among ideas during the analytical phase and aids in the interpretation of findings. Hallinger's (2013) conceptual framework for systematic reviews of research comprised of five questions guided the review of this study as follows:

(1) What are the central topics of interest, guiding questions and goals?; (2) What conceptual perspective guides the review's selection, evaluation and interpretation of the studies?; (3) What are the sources and types of data employed for the review?; (4) How are data evaluated, analyzed and synthesized in the review?; (5) What are the major results, limitations and implications of the review?" (p. 130). 
In terms of identification and selection of sources for review, the researchers collected data through open-ended series of searches by using a wide range of search engines such as Google Scholar, ERIC, Scopus, ScienceDirect and a number of journal publication databases including Emerald and EBSCOHost using a preestablished set of search terms (e-leadership, virtual leadership, leading virtual teams, school ICT leadership and e-leaders) included research publications, conferences paper, book chapter and thesis.

The inclusion criteria to identify published studies in this review are as followed: (1) studies had to be published between 2000 and 2016; (2) be published in English; (3) title focus on e-leadership, virtual leadership, leading virtual teams, school ICT leadership and e-leaders in both education and non-educational setting. Next, each article is examined to determine its match with the inclusion criteria and then classified as "included for review" or "excluded from review". Those studies not meeting the criteria were excluded from this review. Hallinger $(2013$, p. 133) states "there is no magic number that defines the optimal number of papers to be included in a review". Ultimately, forty-five articles (peer-reviewed journal articles, book chapter, conferences paper and thesis) met the inclusion criteria and were read, abstracted and coded for this review.

A "Cross-article analysis template" was designed in MS Word for data collection and data analysis. The use of template increases the reliability of the information collected by multiple researchers (Hallinger, 2013). Information on author, publication year, field, country, focus and variables, design and method, sample and sampling size and findings and suggestions were abstracted and those lacked details regarding any field of interest were coded as "not mentioned". The coded data were used to categorize and organize studies and were arranged across the template horizontally. Findings and suggestions column provide a brief description of each article. Part of the content analysis output is shown in Table 1. Themes were identified by connecting and contrasting the summaries on the "Cross-article analysis template" during data analysis (Szeto, Lee, \& Hallinger, 2015; Voogt, Fisser, Pareja Roblin, Tondeur, \& van Braak, 2013).

\section{RESULTS AND DISCUSSION}

Search engine Google reported 2,320,000 hits under the title "principal leadership" as opposed to 4,000,000 hits for the title "principal e-leadership" (search being conducted on May 30, 2016). In fact, the migration of leadership to e-leadership has been considered a decisive factor in shielding any reform endeavours (Avolio \& Kahai, 2003). At the beginning, the research on e-leadership focuses more on business and non-educational area. This is supported by Mishra, Henriksen, Boltz, \& Richardson (2016) who stated that most research on e-leadership focus mainly on business and management sectors.

For instance, from 2000 to 2004, out of nine articles on e-leadership, eight focuses on non-education and only one article focuses on education which is the one written by Gurr (2004). The author stated that the advancement of technology has changed the context of leadership and highlights the important of a research study to be conducted in educational settings. Additionally, he concluded that there is a need to emphasize on leadership ICT competencies such as effective communication skills, 
interpersonal skills and the ability to cope with distributed leadership, complexity and uncertainty. Thus, e-leadership will become an important part of educational leadership as more ICT environments are developed in educational settings.

According to Lovelace (2015), there is limited current literature on e-leadership that specifically introduced the concept of e-leadership via an empirical study and mainly focuses on anecdotal evidence. Thus, the introduction of e-leadership to the educational settings will be important for empirical research on e-leadership to examine the differences in non-educational settings (Gurr, 2004). Similarly, Carreno (2009) focused on the use of ICT in educational settings, specifically, e-mentoring with reference to the virtual leader and mentor. The author highlights the main strengths and skills needed by effective e-leaders and their importance in the management of educational institutions from a distance. In addition, Jameson (2013) noted that e-leadership is barely identified as an important feature of higher educational institutions. Therefore, there is a need for senior management, middle management and teacher-level strategic leaders to become personally committed to e-leadership.

In between the year 2007 and 2011, there are 10 articles in total, which focused on e-leadership. Three articles from the education sector and the other seven articles published were from non-education setting. A total of 26 articles published between 2012 and 2016, 18 were from the education setting and eight were from the noneducation setting as shown in Table 2 . Across the years, the number of articles increased from $1(2000-2004)$ to $3(2007-2011)$ to $18(2011-2016)$ in the field of education. Thus, the increase in the number of research on e-leadership in educational setting indicated that the field starts to gain prominence.

Table 2: Summary of field of articles

\begin{tabular}{ccc}
\hline Years & Education & Non-education \\
\hline $2000-2004$ & 1 & 8 \\
$2007-2011$ & 3 & 7 \\
$2012-2016$ & 18 & 8 \\
\hline Total & & 45 \\
\hline
\end{tabular}

Contributions of literature on e-leadership either in education or non-education field mainly are from the western countries namely USA, Australia and European countries. However, there are a few studies conducted in Asian countries such as Hong Kong, Taiwan and Malaysia. For instance, Lam \& Woodhead (2012) compared two schools in Hong Kong across eight domains of e-leadership namely: leadership and management, curriculum, learning and teaching, assessment, professional development, extending opportunities for learning, resources and impact on student outcome. They mentioned that introduction of ICT had revealed the underlying values and beliefs about the impact of technology on the leadership of learning.

On the other hand, in order to investigate the perceived e-leadership style change and its consequence in the virtual context in Taiwan, Fan (2013) adopted a $2 \times 2 \times 2$ factorial experiment design through the administration of survey questionnaires to a total of 130 undergraduate students. Results indicated that perception of transformational or transactional leadership style and leadership change was significantly stronger in accord with the assigned situation. In addition, the author 
added that virtual leaders should guide their team members with more understanding and empathy wordings through computer-mediated environment would not only increase members' willingness to propose their ideas but also earn their respect, trust and satisfaction.

In the Malaysian context, Mohd Yusri (2014) intended to build a model of eleadership, intra-team communication and job satisfaction among school leaders in Malaysia based on the theory of three levels of product attributes, consequences and personal values. The theory suggested that the attributes of technology, consequences of value and personal attributes are hierarchically interconnected. Statistical analysis indicated that the e-leadership based on mobile technology is significantly contributed to the intra-team, while the intra-team communication is also positively predicted towards job satisfaction. In addition, Mohd Yusri (2015) indicated that a successful model of e-leadership that can be practiced by school leaders in parallel with the rapid development of mobile technology has been developed. It was found that there were six main factors that are associated with effective e-leadership practices in organizations. The factors are challenges, leadership styles, trust building, training and development, culture, e-leader's skills and guidelines.

\section{Challenges}

Ten articles focused on creating an understanding of broader issues and challenges faced by e-leaders in the virtual environment. Of the 10 articles coded as challenges faced by e-leaders, only one is directly linked to the role of the school leaders with technology integration in school. Lam \& Woodhead (2012) in their paper indicated that both case schools showed e-leadership in the context of connectedness and lifelong learning. Besides, both authors found that the introduction of technology into the schools has revealed the underlying impact of technology on the leadership of learning like a magnifying glass.

\section{Leadership styles}

The second factor is e-leadership styles. Quite a number of studies looked at eleadership from the perspective of distributed leadership (Avolio, Walumbwa, \& Weber, 2009; Carreno, 2014; De Freitas \& Routledge, 2013; Gracia, 2015; Gurr, 2004; Harris et al., 2013; Jameson, 2013, 2014; Ottestad, 2013; Pulley, Sessa, \& Malloy, 2002). However, there are few studies that look at more than one leadership style in a virtual team (Chang \& Lee, 2013; Hambley et al., 2007; Kahai, Jestire, \& Huang, 2013; Lovelace, 2015; Ottestad, 2013). For instance, Ottestad (2013) looked at indicators of school leadership for ICT that carried traits of perspectives from distributed, transformational and pedagogical leadership. The author identified four indicators of school leadership for ICT including digital practice, ICT maturity, assessment and roles with ICT and leadership for collaboration. Those indicators were correlated with teachers' attitude and the time they spend on ICT for administrative use (Ottestad, 2013). 
Table 1: Part of the Content Analysis Output

\begin{tabular}{|c|c|c|c|c|c|c|}
\hline Author & Field & Country & Focus/variables & Design/Method & $\begin{array}{l}\text { Sample } \\
\text { size/Sampling }\end{array}$ & Findings / Suggestion for future study \\
\hline $\begin{array}{l}\text { Avolio, } \\
\text { Kahai, } \\
\text { \&Dodg } \\
\text { e (2000) }\end{array}$ & $\begin{array}{l}\text { Non- } \\
\text { education }\end{array}$ & USA & $\begin{array}{l}\text { E-leadership: } \\
\text { Implications for } \\
\text { theory, research, } \\
\text { and practice }\end{array}$ & Content analysis & Not mentioned & $\begin{array}{l}\text { This article is one of the first instances to use the term "e- } \\
\text { leadership". Authors provide literature reviews and recommendations } \\
\text { for research on e-leadership. Besides, authors provides framework } \\
\text { underpinned by AST to measure the interactive influences including } \\
\text { ICT and lea dership that occur between organisation structures } \\
\text { (reciprocal relationship of ICT and lea dership). AST is based on the } \\
\text { theory that human action is guided by structures, which are defined } \\
\text { as rules and resources that serve as templates for planning and } \\
\text { accomplishing tasks. }\end{array}$ \\
\hline $\begin{array}{l}\text { Kissler } \\
(2001)\end{array}$ & $\begin{array}{l}\text { Non- } \\
\text { education }\end{array}$ & USA & E-lea dership & Content analysis & Not mentioned & $\begin{array}{l}\text { Author stated that e-leaders would face similar problems in adopting } \\
\text { e-business strategy as those fundamental lea dership challenges. Thus, } \\
\text { by providing a review of successful leadership actions would be } \\
\text { beneficial. Author mentioned that evidence from the study will give } \\
\text { important implications for e-lea dership and author divide successful } \\
\text { actions of leadership into } 9 \text { categories, including: organizational } \\
\text { mind share (quick and efficient use of information); future print } \\
\text { (creation and sharing of future vision and direction); organizational } \\
\text { alignment (in respect of leadership, workforce, structure, and } \\
\text { process, with an overall strategy and vision); proximity management; } \\
\text { creative tension; sense of urgency; development of people; leading } \\
\text { by values; and, resistance and air cover. }\end{array}$ \\
\hline $\begin{array}{l}\text { Pulley } \\
\text { \& Sessa } \\
(2001)\end{array}$ & $\begin{array}{l}\text { Non- } \\
\text { education }\end{array}$ & USA & $\begin{array}{l}\text { E-lea dership: } \\
\text { Tackling complex } \\
\text { challenges }\end{array}$ & $\begin{array}{l}\text { Mixed method } \\
\text { (Survey and } \\
\text { interview) }\end{array}$ & $\begin{array}{l}546 \text { leaders } \\
\text { across a wide } \\
\text { array of } \\
\text { industries and } \\
35 \text { in-depth } \\
\text { interview }\end{array}$ & $\begin{array}{l}\text { Explored the impact of digital technology on leadership and } \\
\text { identified e-leadership as a complex challenge that is defined by } 5 \\
\text { key para doxes: (a) swift and mindful; (b) individual and community; } \\
\text { (c) top-down and grass-roots; (d) details and big picture; and (e) } \\
\text { flexible and steady. }\end{array}$ \\
\hline
\end{tabular}


Hambley et al. (2007) examined the applications of transformational and transactional leadership paradigm to virtual teams. Similarly, Chang \& Lee (2013) investigated the influences of transformational and transactional leadership on student's learning performances and Kahai et al. (2013) examined transformational and transactional leadership on cognitive effort and outcomes of participants during collaborative learning in virtual settings. More recently, Lovelace (2015) researched on e-leadership construct of leaders of healthcare organizations from the perspective of servant leadership and transformational leadership style. For a better understanding of e-leadership constructs, the researcher used a mixed method approaches through the administration of two sets of the survey to measure servant leadership and transformational leadership, along with a group interview that uses audio recordings and notes taking. Lovelace's (2015) results indicated a strong positive relationship between the two e-leadership instruments that measure servant leadership and transformational leadership traits.

As we can see from the above discussion, studies of e-leadership focus on the various existing theory of leadership (transformation, distributed, servant, transactional, pedagogic and situational). However, prior literature showed that distributed leadership style is the most adopted style of leadership in virtual settings where researchers concluded that distributed leadership is significantly relevant and important to successfully lead a virtual team (Avolio et al., 2009; Carreno, 2014; Jameson, 2013; Ottestad, 2013).

\section{Trust building}

Subsequently, more than one-fourth of the articles $(n=11)$ focused ontrust-building and the importance of trust among virtual team members. "Trust is important for any team to function and excel, but its importance for virtual teams is even more critical" (Cascio \& Shurygailo, 2003, p.373). Zaccaro \& Bader (2003) stated that effective teams are those that are able to build trust between members and suggested a three-phase model for trust building among virtual team members. Malhotra, Majchrzak, \& Rosen (2007) looked at effective virtual leadership practices and further described that one of it was to establish and maintain trust through the use of ICT. He (2008) found that distrust due to physical absence was one of the main challenges faced by e-leaders and suggested that transformational leadership style has more positive impact on trust among virtual teams.

Avolio, Walumbwa, \& Weber (2009) discussed the effect of e-leadership on trust formation among team members. Savolainen $(2013 ; 2014)$ overviewed trust building in e-leadership and stated that trust building is listed as one of the key leadership skills in this new millennium. Politis (2014) discussed the effect of e-leadership on organizational trust and commitment of virtual teams. Lilian (2014) stated that the main challenges of e-leaders are typically related to trust creation and maintenance. In addition, trust in the leader is one of the constructs where Fan (2013) used to assess the leadership effectiveness. Finally, Jameson (2013, p.909) highlights that "...high trust environments can be enabled to emerge interactively through the development of technological innovations in tandem with e-leadership and good communication". 


\section{Training and development}

Next, Cascio \& Shurygailo (2003) noted that much training and development for virtual work environments is informal in nature. Quite a number of studies pointed out the need for e-leaders to undergo specialized training seminar and program focusing on e-leadership and ICT technology in order to lead effective teams (Zaccaro \& Bader, 2003; Lovelace, 2015). In addition, Jameson (2013) stated that a program of training and professional development based on the framework of eleadership knowledge and skills should be widely developed so that leaders at all levels learn about e-leadership. In Cascio \& Shurygailo's (2003) article, the authors described few examples which might be helpful in formal training such as understand the use of ICT tools to enhance team performances; social protocol; cultural values; how to manage virtual teams and how to provide anonymous participation and feedback when ideas or criticism need to be brought out. Malhotra et al. (2007) mentioned that the outlined of successful virtual leadership practices can be used to establish a foundation for training and developing future virtual team leaders whereas Park \& Popescu (2014) suggested that training for e-leaders should focus on the use of different types of technology, implement formal communication rules, capitalize team member background and experience and transform them into strength.

On the other hand, Mishra et al. (2016) found that there is a significant gap in how we perceive about teacher professional development in the domain of ICT. Additionally, research has shown that a teacher's beliefs and attitudes are often strong indicators of their planning, instructional decisions, classroom practices and their ability to use technology (Bullock, 2004; Celep \& Tülübaş, 2014; Lu, Yu, Liu, \& Yao, 2003; Mishra et al., 2016). However, the most significant influence on how teachers' actually use the ICT is the knowledge they have on the specific educational technology. Thus, teacher's education and development are very important as well and there is a need to focus on the development of all four kinds of knowledge: namely, know-what, know-why, know-how and know-who (Mishra et al., 2016).

\section{Culture}

Few studies focused on creating a broader understanding of issues related to cultural differences in different context and the implications of this to the e-leaders. Jameson (2013) highlights the importance of intercultural skills of e-leaders to build high trust among team members in the ICT-mediated environment. Fan (2013) noted that the characteristics of e-leadership may vary across a variety of cultures. Likewise, He (2008) researched on various factors including culture differences that contribute to team conflict and performance. The author stated that e-leaders can benefit from a better understanding of factors that trigger conflicts among team members which in turn might affect the team performance.

Indeed, according to Pulley \& Sessa (2001), the greatest e-leadership challenge among all is how to create a culture that allows all the voices of leadership to be heard. Additionally, Park \& Popescu (2014) empirical findings stated that cultural differences among virtual team members increase the complexity of leading virtually. Both authors added that effective e-leaders are those able to create a culture where people are not afraid to speak up, be open-minded and provide feedback when necessary. 


\section{E-Leader's Skills \& Guidelines}

E-leader's skills and guidelines are one of the six main factors that contributed to effective e-leadership practices in organizations. ICT-mediated environment emphasize more on the leader's ability to be able to convey exemplary interpersonal skills through the associated technology (Gurr, 2004). On the one hand, Cascio \& Shurygailo (2003) mentioned that effective e-leader's behaviours fall into three key areas namely, virtual collaborative skills, virtual socialization skills and virtual communication skills. On the other hand, Jameson (2013) indicated that e-leader's interpersonal and intercultural skills in which the leader is able to build a high level of trust are very important. Besides, the author provides a new framework of eleadership skills and knowledge needed by e-leaders in higher education.

Many studies focused on understanding e-skills needed by e-leaders to lead a virtual team effectively (Carreno, 2009, 2014; DasGupta, 2011; Lilian, 2014; Park \& Popescu, 2014; He, 2008; Savolainen, 2013, 2014). Carreno $(2014,2009)$ focused on strengths and skills needed by the virtual leader in the management of education at a distance whereas DasGupta (2011) discussed briefly e-skills required by successful e-leaders based on prior research on e-leadership. Savolainen (2013) focused on discussing the important skills for technology-mediated management in the 21st century. Specifically, the author discussed trust-building within an e-leader-follower relationship, e-leadership characteristics and skills in e-context.

Qualitative data collected by Savolainen (2014) showed that e-leaders mainly described themselves as an expert leader where their followers might influence their leadership style and work. They were more of coaches and mentors than overseers. Leading by example became one of the most influential skills and features required by successful e-leaders. Besides, Politis (2014) highlights the need for virtual leaders to be adequately trained on virtual communication skills to facilitate information sharing between virtual workers.

Finally, discussion on guidelines for e-leaders and effective e-leadership practices. Pulley et al. (2002) provided guidelines for the effective e-leadership program including using initial face-to-face meeting and create communication strategies, be explicit about structure and logistics, keep the team small, give and receive feedback, create frequent feedback checkpoints and teach a behavioural model that participants can practice face-to-face and online. On the other hand, Cowan (2014) provided eight guiding principles of e-leadership for nurse leaders. The author stated that e-leaders must have trusting relationship with team members; enhance visibility; understand social-emotional aspects of the team; maintain healthy team interaction; establishing efficient communication norms; communicate contextual and relevant information; address concerns, provide feedback and recognition, as well as resolve performance issues and sensitive to virtual team cultural norms to better manage conflict. Through a critical review of the literature, a model is proposed for e-leadership based on theories and research evidence. Besides, variables that are associated with e-leadership are included in the model. Figure 1 showed the proposed model of e-leadership.

As illustrated in Figure 1, there are six main factors that are associated with effective e-leadership practices in organizations. The factors are challenges, leadership styles, trust building, training and development, culture, e-leader's skills and guidelines. 
Additionally, the six main factors proposed in Figure 1 were the key to e-leadership outcomes such as organizational trust, commitment, performances and satisfaction of the follower within the organization. Through an extensive review of the literature, it was found that there is missing link that needs to be addressed.

\section{THE MISSING LINK FOR FUTURE STUDIES}

A total review of 45 published literature on e-leadership revealed that researches mainly focused on the perceptions of leaders whereas the perceptions of teachers are seldom being asked. Although prior researches on virtual teams have partly examined e-leadership from team member's point of view, the emphasis were more on leader's point of view and less on member's perceptions. According to Mohd Rozi (2012), teacher's perception of principal's leadership is critical because teachers and principals work together closely, and teachers are directly affected by the school principals. Besides, it was found that almost half of the literature are content analysis paper and literature on e-leadership that specifically introduced the concept of e-leadership via an empirical study are relatively scarce. In addition, there is relatively limited current literature on e-leadership that relied on qualitative method.

Furthermore, an e-leadership concept often explores the dominant conceptions of leadership by focusing on the existing theory of leadership. According to Mishra et al. (2016), existing theory of leadership might be necessary but is not sufficient for successful leadership in virtual environments. Although the goals of leadership may not have changed, but e-leaders pursue achieving goals through people via virtual environments which in turn change the traditional leader-follower relationship (Savolainen, 2014). Savolainen (2014) also indicated that e-leadership represents both a new kind of managerial work and context for studying leadership. Pulley \& Sessa (2001) stated that ICT impact leadership to a certain extent and identified eleadership as a complex challenge. It shows that there is a gap between uptake of technological innovations in education and professional development and research on the educational technology leadership.

In order to ensure the field of e-leadership continues to mature, it is proposed that significantly more research should be carried out in this field. Future studies should seek to identify how the characteristics of effective e-leaders may be achieved and more empirical-based data is needed in order to align the practice-based indicators with more overarching theoretical concepts. In order to ensure that leaders at all levels learn about e-leadership in educational technology, considerably more attention is needed on research and development in e-leadership and the related fields of educational technology.

\section{CONCLUSION}

The above content analysis study tried to propose a model of e-leadership practices and variables that are associated with e-leadership. It mainly focused on challenges, e-leadership styles, trust building, training and development, e-leader's skills and guidelines, culture and e-leadership outcomes. It was found that empirical studies on e-leadership are scarce and research mainly focused on the perceptions of leaders and relied less on qualitative method. Furthermore, an e-leadership concept often explored the dominant conceptions of leadership by focusing on the existing theory of leadership. This is an important point to show that there is limited current 
literature on the concept of e-leadership. By referring to the e-leadership model proposed in this study, e-leadership appears to be the key to organizational trust, commitment, performances and satisfaction of the followers within the organization. Further research can build up from this study by referring to the proposed model of e-leadership to explore this topic further. 


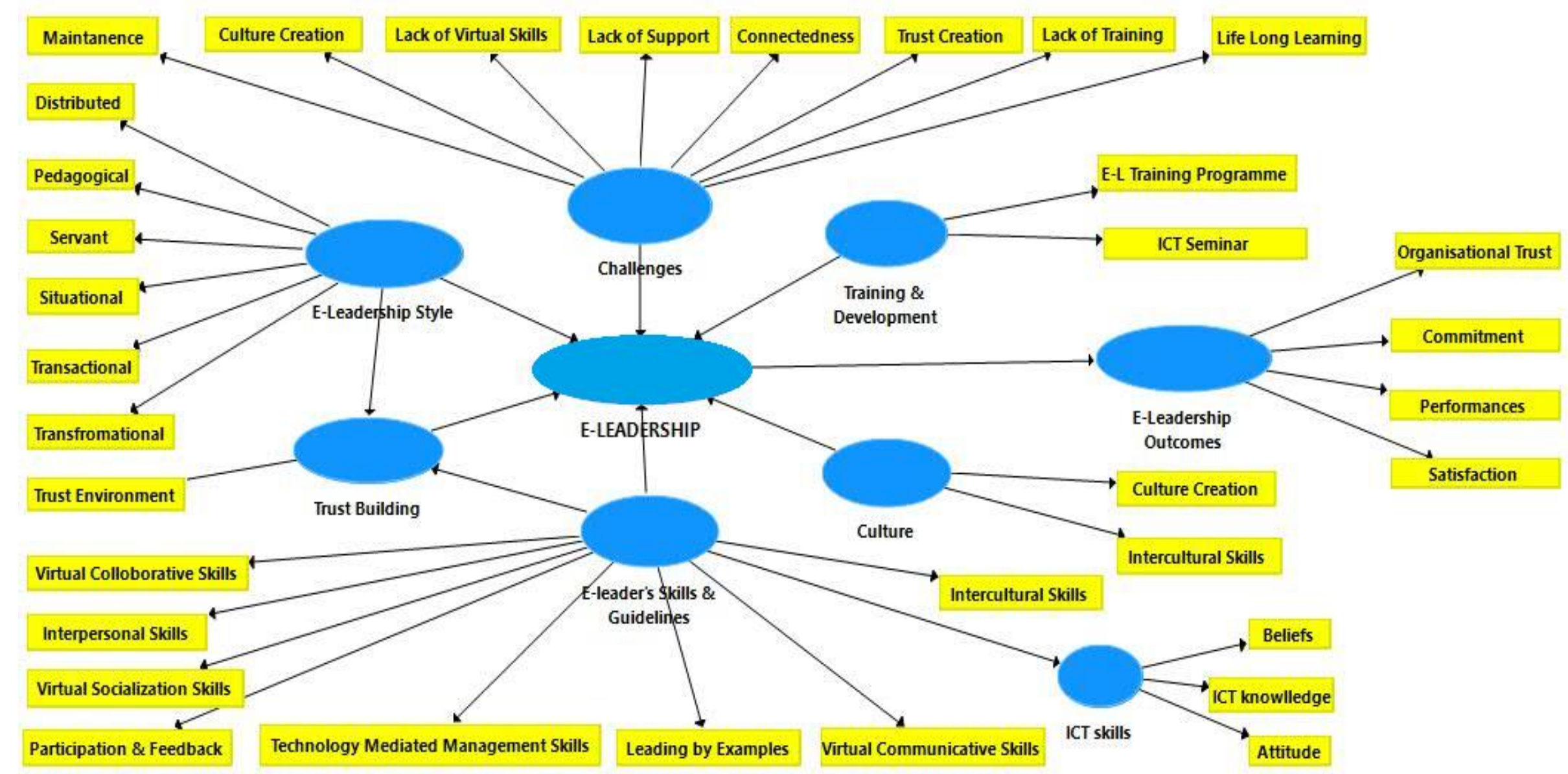

Figure 1: Proposed model of e-leadership 


\section{REFERENCES}

Adeyemi, T. O., \& Olaleye, F. O. (2010). Information communication and technology (ICT) for the effective management of secondary schools for sustainable development in Ekiti State, Nigeria. American-Eurasian Journal of Scientific Research, 5(2), 106-113.

Avolio, B. J., Kahai, S., \& Dodge, G. E. (2000). E-leadership: Implications for theory, research, and practice. The Leadership Quarterly, 11(4), 615-668.

Avolio, B. J., \& Kahai, S. S. (2003). Adding the "e" to e-leadership: How it may impact your leadership. Organizational Dynamics, 31(4), 325-338.

Avolio, B. J., Sosik, J. J., Kahai, S. S., \& Baker, B. (2014). E-leadership: Re-examining transformations in leadership source and transmission. The Leadership Quarterly, 25(1), 105-131. https://doi.org/10.1016/j.leaqua.2013.11.003

Avolio, B. J., Walumbwa, F. O., \& Weber, T. J. (2009). Leadership: Current theories, research, and future directions. Annual Review of Psychology, 60(1), 421-449. https://doi.org/10.1146/annurev.psych.60.110707.163621

Bullock, D. (2004). Moving from theory to practice: An examination of the factors that preservice teachers encounter as the attempt to gain experience teaching with technology during field placement experiences. Journal of Technology and Teacher Education, 12(2), 211-237.

Carreño, I.D.V.G. (2009). E-mentoring and e-leadership importance in the quality of distance and virtual education Century XXI. In A. Méndez Vilas, A. Solano Martín, J. Mesa González, \& J. A. Mesa González (Eds.), Research, Reflections and Innovations in Integrating ICT in Education (pp. 728-732). Badajoz, Spain: Formatex.

Carreño, I.D.V.G. (2014). Emergent leadership: E-leadership implications for virtual education. Revista de Estudios Para El Desarrollo Social de La Comunicación, 10, 308-324. https://doi.org/10.15213/redes.n10.p309

Cascio, W. F., \& Shurygailo, S. (2003). E-leadership and virtual teams. Organizational Dynamics, 31(4), 362-376.

Celep, C., \& Tülübaş, T. (2014). Effect of principals' technological leadership on teachers' attitude towards the use of educational technologies. In D. Passey \& A. Tatnall (Eds.), Key competencies in ICT and informatics. implications and issues for educational professionals and management (pp. 247-258). Berlin, Heidelberg: Springer Berlin Heidelberg.

Chang, W.-L., \& Lee, C.-Y. (2013). Virtual team e-leadership: The effects of leadership style and conflict management mode on the online learning performance of students in a business-planning course. British Journal of Educational Technology, 44(6), 986-999.

Cowan, L. D. (2014). E-Leadership: Leading in a virtual environment - Guiding principles for nurse leaders. Nursing Economics, 32(6), 312-322.

DasGupta, P. (2011). Literature review: e-leadership. Emerging Leadership Journeys, 4(1), 1-36.

Fan, K.-T. (2013). Investigating the perceived of e-leadership style change and its consequence in virtual context. Paper presented at the Proceedings of the 2013 International Conference on Technology Innovation and Industrial Management, Phuket, Thailand, 29-31 May (pp. 298-318). Thailand: ToKnowPress.

De Freitas, S., \& Routledge, H. (2013). Designing leadership and soft skills in educational games: The e-leadership and soft skills educational games design model (ELESS). British Journal of Educational Technology, 44(6), 951-968. 
Ghani, Muhammad Faizal A. (2013). Educational management in Malaysia. Kuala Lumpur: University of Malaya Press.

Gracia, I. (2015). Emergent leadership: is e-leadership importance in the quality of virtual education? Revista Iberoamericana de Educación a Distancia, 18(1), 25-44.

Gronow, M. (2007). ICT leadership in school education. Paper presented at the Australian Catholic University Conference, Sydney, Australia.

Gurr, D. (2004). ICT, leadership in education and e-leadership. Discourse: Studies in the Cultural Politics of Education, 25(1), 113-124. https://doi.org/10.1080/0159630042000178518.

Hallinger, P. (2013). A conceptual framework for systematic reviews of research in educational leadership and management. Journal of Educational Administration, 51(2), 126-149. https://doi.org/10.1108/09578231311304670

Hambley, L. A., O’Neill, T. A., \& Kline, T. J. B. (2007). Virtual team leadership: The effects of leadership style and communication medium on team interaction styles and outcomes. Organizational Behavior and Human Decision Processes, 103(1), 1-20. https://doi.org/10.1016/j.obhdp.2006.09.004

Hanna, N. K. (2007). E-Leadership institutions for the knowledge economy. (World Bank Institute Working Paper). Washington, DC: World Bank. Retrieved from http://info.worldbank.org/etools/docs/library/241087/ELeadershiplnstitution sFinal.pdf

Harris, A., Jones, M., \& Baba, S. (2013). Distributed leadership and digital collaborative learning: A synergistic relationship? British Journal of Educational Technology, 44(6), 926-939.

$\mathrm{He}$, R. (2008). E-leadership strategy in virtual organizations and virtual teams. (Unpublished Master's Thesis). Helsinki University of Technology, Finland.

Jameson, J. (2013). E-Leadership in higher education: The fifth "age" of educational technology research. British Journal of Educational Technology, 44(6), 889915. https://doi.org/10.1111/bjet.12103

Jameson, J. (2014). Distributed e-leadership and trust: The visibility/invisibility paradox in the ecology of online school communities. In International Congress for School Effectiveness and Improvement. Yogyakarta, Indonesia.

Kahai, S., Jestire, R., \& Huang, R. (2013). Effects of transformational and transactional leadership on cognitive effort and outcomes during collaborative learning within a virtual world. British Journal of Educational Technology, 44(6), 969-985.

Lam, P. H. C., \& Woodhead, P. (2012). A critical analysis of the challenges facing eleaders in the 21st century: A review and comparison of the information and communication technology development of a public school and a public independent school in Hong Kong. International Journal of Learning, 18(3), 131-146.

Leithwood, K., Louis, K.S., Anderson, S. \& Wahlstrom, K. (2004). How leadership influences student learning: A review of research for the Learning from Leadership project. New York: The Wallace Foundation.

Leong, M. W., Chua, Y. P., Kannan, S., \& A. Maulod, S. (2016). Principal Technology Leadership Practices and Teacher Acceptance of School Management System (SMS). Jurnal Pemimpin, 11(1), 89-103.

Lilian, S. C. (2014). Virtual teams: Opportunities and challenges for e-leaders. Procedia - Social and Behavioral Sciences, 110, 1251-1261. https://doi.org/10.1016/j.sbspro.2013.12.972 
Lovelace, K.J. (2015). A Case Study of E-Leadership Constructs: An Assessment of Leadership in a Healthcare Organization. Retrieved from ProQuest Dissertations Publishing (10006420).

Lu, J., Yu, C.S., Liu, C., \& Yao, J. E. (2003). Technology acceptance model for wireless Internet. Internet Research, 13(3), 206-222.

Malhotra, A., Majchrzak, A., \& Rosen, B. (2007). Leading virtual teams. Academy of Management Perspectives, 21(1), 60-70.

Mcleod, S., \& Richardson, J. W. (2011). The dearth of technology leadership coverage. Journal of School Leadership, 21(2), 216-240.

Mishra, P., Henriksen, D., Boltz, L. O., \& Richardson, C. (2016). E-leadership and teacher development using ICT. In R. Huang, Kinshuk, \& J. K. Price (Eds.), ICT in Education in Global Context (pp. 249-266). Berlin, Heidelberg: Springer Berlin Heidelberg.

Mohamad Mohsin, S. F. A., Hassan, R., \& Ariff, A. F. (2014). Amalgamation of Dale's Cone of Experience, Bloom's Taxonomy and 21st Century Skills Through Virtual Learning Environment. Journal of Contemporary Management Sciences, 3(7), 88-99.

Mohammed Sani, I., Ahmad Zabidi, A., \& Husaina Banu, K. (2013). Smart principals and smart schools. Procedia - Social and Behavioral Sciences, 103, 826-836. https://doi.org/10.1016/j.sbspro.2013.10.404

Mohd Rozi, I. (2012). Teachers' perceptions of principal leadership styles and how they impact teacher job satisfaction. Retrieved from ProQuest Dissertations Publishing (3509653).

Mohd Yusri, I. (2014). Model of E-Leadership, Intra-team Communication and Job Satisfaction among School Leaders in Malaysia. Mediterranean Journal of Social Sciences, 5(23), 1927-1931. https://doi.org/10.5901/mjss.2014.v5n23p1927

Mohd Yusri, I. (2015). Model of Virtual Leadership, Intra-team Communication and Job Performance Among School Leaders in Malaysia. Procedia - Social and Behavioral Sciences, 186, 674-680. https://doi.org/10.1016/j.sbspro.2015.04.126

Ottestad, G. (2013). School leadership for ICT and teachers' use of digital tools. Nordic Journal of Digital Literacy, 8(1-2), 107-125.

Park, A., \& Popescu, L. (2014). E-leadership for project managers: Virtual leadership and trust-building for perceived project success. Unpublished Master Thesis, Jonkoping University, Sweden.

Politis, J. (2014). The effect of e-leadership on organisational trust and commitment of virtual teams. In The 10th European Conference on Management, Leadership \& Governance (ECMLH2014) (pp. 254-261). University of Applied Science, Zagreb, Republic of Croatia.

Pulley, M., L., \& Sessa, V. I. (2001). E-leadership: Tackling complex challenges. Industrial and Commercial Training, 33(6), 225-230. https://doi.org/10.1108/00197850110405379

Pulley, M., L., Sessa, V. I., Fleenor, J. W., \& Pohlmann, T. (2001). E-leadership: Separating the reality from the hype. Center for Creative Leadership, 21(4), 124. https://doi.org/10.1002/lia.1007

Pulley, M., L., Sessa, V. I., \& Malloy, M. (2002). E-leadership: A two-pronged idea. $T+D, 56(3), 34-47$.

Purvanova, R. K., \& Bono, J. E. (2009). Transformational leadership in context: Faceto-face and virtual teams. The Leadership Quarterly, 20(3), 343-357. https://doi.org/10.1016/j.leaqua.2009.03.004 
Robertson, S. L. (2005). Re-imagining and rescripting the future of education: global knowledge economy discourses and the challenge to education systems. Comparative Education, 41(2), 151-170. https://doi.org/10.1080/03050060500150922

Savolainen, T. (2013). Trust building in e-leadership - Important skill for technologymediated management in the 21st century. In Proceedings of the International Conference on Management, Leadership and Governance (pp. 288-296). Bangkok, Thailand.

Savolainen, T. (2014). Trust-building in e-leadership: A case study of leaders' challenges and skills in technology-mediated interaction. Journal of Global Business Issues, 8(2), 45-56.

Spring, J. (2008). Research on Globalization and Education. Review of Educational Research, 78(2), 330-363. https://doi.org/10.3102/0034654308317846

Szeto, E., Lee, T. T. H., \& Hallinger, P. (2015). A systematic review of research on educational leadership in Hong Kong, 1995-2014. Journal of Educational Administration, 53(4), 534-553. https://doi.org/10.1108/JEA-03-2015-0027

Voogt, J., Fisser, P., Pareja Roblin, N., Tondeur, J., \& van Braak, J. (2013). Technological pedagogical content knowledge - a review of the literature. Journal of Computer Assisted Learning, 29(2), 109-121. https://doi.org/10.1111/j.1365-2729.2012.00487.x

Walker, A., \& Hallinger, P. (2015). A synthesis of reviews of research on principal leadership in East Asia. Journal of Educational Administration, 53(4), 554-570. https://doi.org/10.1108/JEA-05-2015-0038

Zaccaro, S. J., \& Bader, P. (2003). E-leadership and the challenges of leading e-teams: Minimizing the bad and maximizing the good. Organizational Dynamics, 31(4), 377-387. 